\title{
A Modified Sodium Metabisulfite Method to Distinguish Sickle Cell Disease from Sickle Cell Trait for Use in Underdeveloped Countries
}

The objective of this study was to develop a simple, inexpensive, and rapid confirmatory test using a sodium metabisulfite microscopic method to distinguish AS from SS genotype in patients testing positive for hemoglobin S. Equal volumes of de-identified EDTA blood and $2 \%$ sodium metabisulfite were mixed, placed on a microscope slide with coverslip, and observed for sickling at 30-minute intervals over 3 hours. Sickle cells were enumerated/200 RBCs under 100x oil immersion and placed into 4 Likert categories (1+-4+) based on degree of sickling. In AS samples, $2+$ and $3+$ sickle cells rose most rapidly while $4+$ sickle cells showed the steepest rise in the SS samples. Based on these data the number of $4+$ sickle cells were counted every 30-minutes over 3 hours in 5 AS and 28 SS samples at 37 degrees Celsius. Mean number of 4+ sickle cells in AS samples were 4.75/200 at 2 hours and $17.75 / 200$ at 3 hours whereas SS samples yielded 78.29/200 at 2 hours and $115.43 / 200$ at 3 hours. Two-hour incubation showed a statistical difference $(P=0.00024)$ between groups in the shortest time and may be used to distinguish SS from AS genotypes. More testing is needed to determine cutpoints to distinguish genotype. 